\title{
Retinal vasculopathy with cerebral leukoencephalopathy and systemic manifestations
}

INSERM

\section{Source}

INSERM. (1999). Orphanet: an online rare disease and orphan drug data base. Retinal vasculopathy with cerebral leukoencephalopathy and systemic manifestations.

ORPHA:247691

Retinal vasculopathy and cerebral leukodystrophy (RVCL) is an inherited group of small vessel diseases comprised of cerebroretinal vasculopathy (CRV), hereditary vascular retinopathy (HRV) and hereditary endotheliopathy with retinopathy, nephropathy and stroke (HERNS; see these terms); all exhibiting progressive visual impairment as well as variable cerebral dysfunction. 